\title{
Circulating $T$ cell subsets are associated with clinical outcome of anti-VEGF-based 1 st-line treatment of metastatic colorectal cancer patients: a prospective study with focus on primary tumor sidedness
}

Beatrix Bencsikova ${ }^{1,2}$, Eva Budinska², Iveta Selingerova ${ }^{2,3}$, Katerina Pilatova ${ }^{2,3}$, Lenka Fedorova ${ }^{3}$, Kristina Greplova ${ }^{2,3}$, Rudolf Nenutil ${ }^{2,4}$, Dalibor Valik ${ }^{2,3}$, Radka Obermannova ${ }^{1,2}$, Michael A. Sheard ${ }^{2}$ and Lenka Zdrazilova-Dubska ${ }^{2,3^{*}}$ (D)

\begin{abstract}
Background: In a prospective study with long-term follow-up, we analyzed circulating T cell subsets in patients with metastatic colorectal cancer (mCRC) in the context of primary tumor sidedness, KRAS status, and clinical outcome. Our primary goal was to investigate whether baseline levels of circulating $T$ cell subsets serve as a potential biomarker of clinical outcome of mCRC patients treated with an anti-VEGF-based regimen.

Methods: The study group consisted of 36 patients with colorectal adenocarcinoma who started first-line chemotherapy with bevacizumab for metastatic disease. We quantified T cell subsets including Tregs and CD ${ }^{+} \mathrm{T}$ cells in the peripheral blood prior to therapy initiation. Clinical outcome was evaluated as progression-free survival (PFS), overall survival (OS), and objective response rate (ORR).
\end{abstract}

Results: 1) mCRC patients with KRAS wt tumors had higher proportions of circulating CD8 ${ }^{+}$cytotoxic T cells among all T cells but also higher measures of T regulatory (Treg) cells such as absolute count and a higher proportion of Tregs in the $\mathrm{CD}^{+}$subset. 2) A low proportion of circulating Tregs among CD4 ${ }^{+}$cells, and a high CD8:Treg ratio at initiation of VEGF-targeting therapy, were associated with favorable clinical outcome. 3) In a subset of patients with primarily right-sided $\mathrm{mCRC}$, superior PFS and OS were observed when the CD8:Treg ratio was high.

Conclusions: The baseline level of circulating immune cells predicts clinical outcome of 1st-line treatment with the anti-VEGF angio/immunomodulatory agent bevacizumab. Circulating immune biomarkers, namely the CD8:Treg ratio, identified patients in the right-sided $\mathrm{mCRC}$ subgroup with favorable outcome following treatment with 1stline anti-VEGF treatment.

Keywords: Metastatic colorectal cancer, T cell subsets, Regulatory T cells, Antitumor immune response, Anti-VEGF, Primary colorectal carcinoma sidedness

\footnotetext{
* Correspondence: dubska@mou.cz

${ }^{2}$ Regional Centre for Applied Molecular Oncology, Masaryk Memorial Cancer

Institute, Brno, Czech Republic

${ }^{3}$ Department of Laboratory Medicine, Masaryk Memorial Cancer Institute,

Brno, Czech Republic

Full list of author information is available at the end of the article
}

(c) The Author(s). 2019 Open Access This article is distributed under the terms of the Creative Commons Attribution 4.0 International License (http://creativecommons.org/licenses/by/4.0/), which permits unrestricted use, distribution, and reproduction in any medium, provided you give appropriate credit to the original author(s) and the source, provide a link to the Creative Commons license, and indicate if changes were made. The Creative Commons Public Domain Dedication waiver (http://creativecommons.org/publicdomain/zero/1.0/) applies to the data made available in this article, unless otherwise stated. 


\section{Background}

Immune cells play a crucial role in control of tumor growth, potentially leading to elimination of cancer cells even while immunosuppression contributes to evasion by malignant cells. Cytotoxic $\mathrm{CD}^{+} \mathrm{T}$ cells (CTLs) represent one of the most important effectors of anti-cancer immunity [1]. Accumulation of $\mathrm{CD}^{+}$cells in solid tumors of various origins including colorectal carcinoma [2-6] has been associated with favorable prognosis and has led to definition of the immunoscore concept that is now emerging in clinical practice in the management of colorectal cancer $[7,8]$.

Regulatory T cells (Tregs) prevent immune hypersensitivity and extensive inflammatory responses. However, through their immunosuppressive properties, Tregs can contribute to escape of tumor cells from immune surveillance [9]. A connection between a high number of Tregs and worse prognosis has been described in several tumor types (reviewed in [10]). There are at least two major subsets of Tregs; natural Treg cells (nTregs) that are generated in the thymus and are constitutively present in blood and lymphoid organs, and induced (or inducible) Tregs (iTregs) that develop outside of the thymus from naïve $\mathrm{T}$ cells during immune responses [9]. nTregs can be recognized by their $\mathrm{CD}^{+} \mathrm{CD}^{+} 5^{+} \mathrm{FoxP}^{+} \mathrm{CD} 127^{\text {low/- }}$ neuropilin $^{+}$surface immunophenotype $[9,11]$. In cancer patients, Tregs can be detected in both the peripheral blood circulation and in the tumor microenvironment (TME), although mechanisms regulating the homing of Tregs into and from the TME are not yet fully elucidated. Nevertheless, in colon cancer patients, cancer-associated circulating Tregs have been shown to inhibit proliferation of autologous $\mathrm{T}$ cells [12] and effector $\mathrm{T}$ cell migration into tumors through an adenosine-dependent mechanism [13]. Moreover, the TME and gut microbiome contribute to Treg plasticity and heterogeneity $[14,15]$ and also consequently to the differential prognostic role of Tregs in colorectal cancer [16-18]; for example, in the context of primary colorectal cancer, Tregs may play both an anti-inflammatory and also a potentially anti-cancer role. In metastatic CRC, as well as other cancer types including breast cancer [19], pancreatic cancer [20], and head-andneck squamous cell cancer [21], elevated numbers of circulating Tregs may be related to worse prognosis.

$\mathrm{CRC}$ is a heterogeneous disease that develops through different molecular pathways affecting distinct gene expression, tumor and TME phenotype, and tumor behavior [22-25]. Consensus molecular subtype (CMS) numbers 1-4 have been associated with distinct immune characterization, as 1) immune activated, highly immunogenic CMS1 tumors of hypermutated microsatellite instable origin with increased infiltration of immune effector cells into the TME [26-28], 2) canonical CMS2 and metabolic CMS3 subtypes which are generally immune-ignorant, and 3) mesenchymal CMS4 tumors with inflamed, immune-tolerant TMEs representing the subtype with dominant immunosuppressive features (TGF- $\beta$, myeloid-derived suppressor cells / MDSC, Tregs, Th17).
Metastatic colorectal cancer is an incurable disease treated in a palliative setting by chemotherapy or chemotherapy plus the anti-VEGF antibody bevacizumab as a tumor angiogenesis modifying agent. Median progression-free survival is reported to be 11.5 months and median overall survival is 29.5 months from initiation of first line (1st-line) therapy with bevacizumab and chemotherapy [29]. Together with its angiomodulatory properties, bevacizumab may influence immune parameters including cells of the adaptive immune response. Bevacizumab partially reversed VEGF-induced inhibition of dendritic cell development [30, 31] and VEGF-associated increases in Tregs [32]. It has also been reported that bevacizumab can directly decrease the level of Tregs and impair their function via VEGF receptors expressed on the surface of Tregs [33]. Finally, bevacizumab-based therapy was shown to increase circulating $\mathrm{B}$ and $\mathrm{T}$ cells and these effects were associated with better clinical outcome in mCRC [34].

In a prospective study, we analyzed circulating $\mathrm{T}$ cell subsets in patients with metastatic colorectal cancer in the context of primary tumor sidedness, KRAS status, and clinical outcome. Our primary goal was to investigate whether baseline levels of circulating immune cells could be a potential biomarker of the clinical outcome of $\mathrm{mCRC}$ patients treated with an anti-VEGF-based regimen.

\section{Methods}

\section{Study group}

The prospective study group consisted of 36 patients with histologically confirmed KRAS-tested metastatic adenocarcinoma of colon or rectum who began 1st-line treatment for metastatic disease between November 2008 and May 2013. A flow chart of patient enrollment with detailed inclusion and exclusion criteria is shown in Fig. 1. Briefly, consecutive patients were older than 18 years, had an Eastern Cooperative Oncology Group performance status of $0 / 1 / 2$, and signed inform consent. Exclusion criteria were: known alteration of immune system (active infections or autoimmune disorder); treatment with G-CSF; contraindication to treatment with bevacizumab or its discontinuation; prior chemotherapy (CTx) for advanced disease, or adjuvant CTx less than 6 months before enrollment onto study, cancer multiplicity. Choice of chemotherapy regimen was at the physicians' discretion. Bevacizumab was administered at a dose of $5 \mathrm{mg} / \mathrm{kg}$ IV with the 2-week regimen or at a dose of $7.5 \mathrm{mg} /$ $\mathrm{kg}$ IV with the 3-week regimen. Patients' responses to treatment and tumor measurements were evaluated with computer tomography scan by a staff radiologist according to RECIST criteria. PFS was defined as the time from the beginning of treatment until the first observation of disease progression or death from any cause, while OS was defined as the time from the beginning of treatment until death from any cause. Patients were followed-up until death or loss to follow-up. Survival rates were last updated in March 2018. ORR was defined as the proportion of patients who have a 


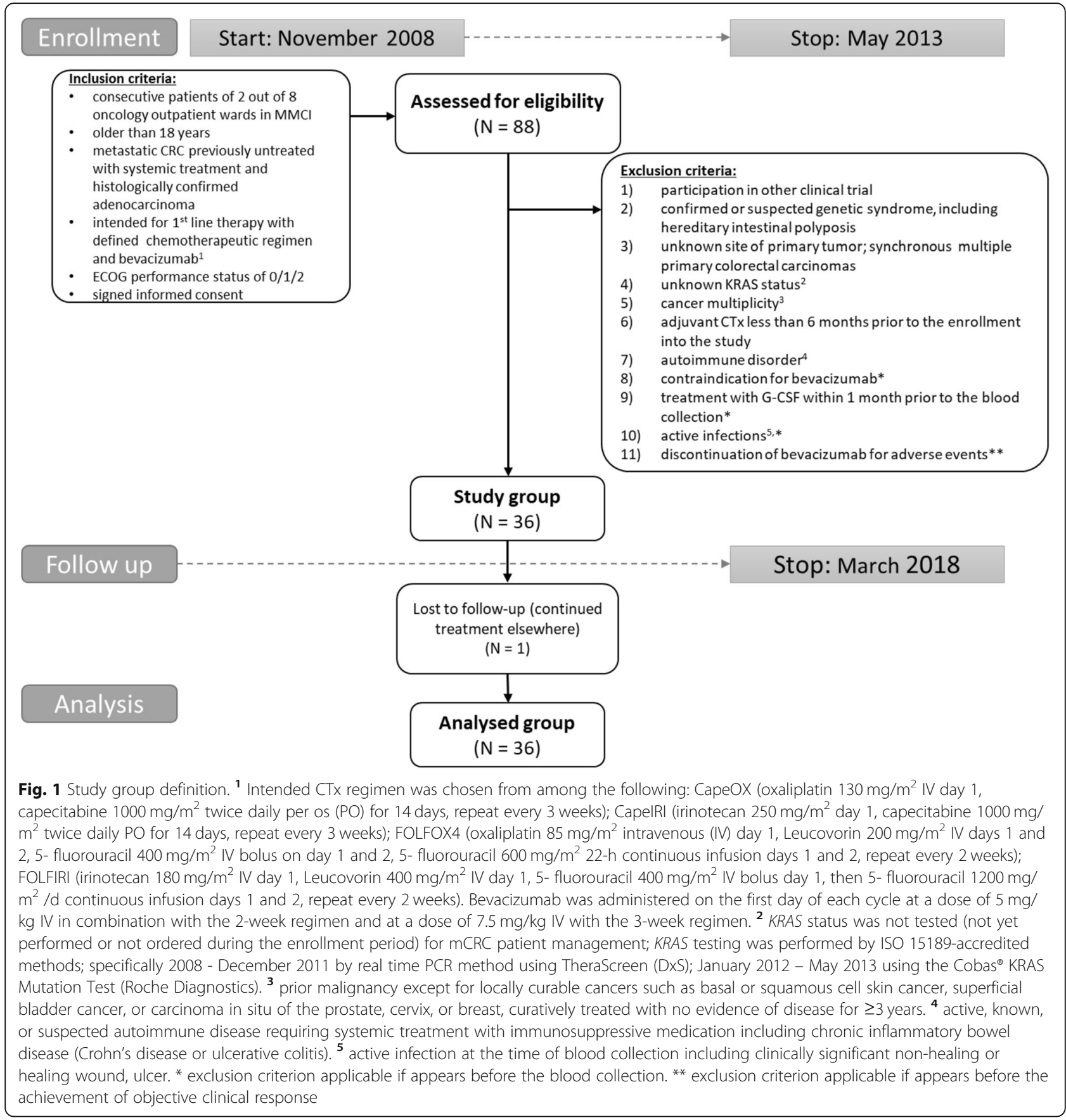

partial or complete response to treatment. Baseline characteristics of patients are summarized in Additional file 1: Table S1.

\section{Sample collection and lymphocyte count evaluation}

Peripheral blood specimens were collected at initiation of anti-VEGF treatment in a $2.6 \mathrm{~mL} \mathrm{~S}$-Monovette ${ }^{\curvearrowleft}$ tube with $K_{3}$ EDTA anticoagulant (Sarstedt, catalog number 04.1901) in a phlebotomy room in close proximity to the laboratory where analysis was performed. Blood specimens were mixed for several minutes on a roller mixer. Immediately after that, absolute lymphocyte count was obtained from the complete blood count by a differential analyzer Sysmex XE 5000 (Sysmex Corporation, Japan). Absolute lymphocyte count was used for calculation of the absolute count of $\mathrm{T}$ cell subsets.

\section{Flow cytometry - T cell subset quantification}

Lymphocyte subsets were evaluated within $3 \mathrm{~h}$ of blood collection. For Treg detection as $\mathrm{CD} 3^{+} \mathrm{CD} 4^{+} \mathrm{CD} 25^{+} \mathrm{CD} 127^{-/ \text {low }+}$ cells and $\mathrm{CD}^{+}{ }^{+} \mathrm{T}$ cell detection, $50 \mu \mathrm{L}$ of whole blood was 
stained with a premixed cocktail of conjugated mAbs (Beckman Coulter) for the following markers, CD3-FITC (clone UCHT1), CD25-PC5 (clone B1.49.9), CD4-PC7 (clone 13B8.2), and CD127-PE (clone R34.34) in concentrations according to manufacturer instructions. The gating strategy for $\mathrm{CD}^{+} \mathrm{CD} 4^{+} \mathrm{CD} 25^{+} \mathrm{CD} 127^{- \text {low }}$ cells including details on gating set-up and the analytical and statistical comparability of $\mathrm{CD} 25^{+} \mathrm{CD} 127^{- \text {low }+}$ and $\mathrm{CD} 25^{+} \mathrm{FoxP}^{+}$quantification approaches are shown in Additional file 1: Figure S1. $\mathrm{CD}^{+}$cells were detected using $50 \mu \mathrm{L}$ of whole blood stained with tetraCHROME CD45-FITC/CD4-PE/CD8$\mathrm{ECD} / \mathrm{CD} 3-\mathrm{PC} 5$ multi-color reagent (Beckman Coulter) in concentrations according to the manufacturer instructions. After a 15 min staining for Tregs or $\mathrm{CD}^{+} \mathrm{T}$-cells in the dark, red blood cells were lysed for $15 \mathrm{~min}$ in the dark by adding $600 \mu \mathrm{L}$ of VersaLyse Lysing Solution (Beckman Coulter, France). Cells were subsequently analyzed using a Cytomics FC 500 flow cytometer, hardware compensation and CXP software (Beckman Coulter, USA).

\section{Statistical analysis}

Wilcoxon two-sample two-tailed test was used to compare continuous variables between the two groups in the Results section, part I. Survival probabilities were estimated using the Kaplan-Meier method in the Results section part II and III. Log-rank test was used to assess the association of categorical variables with survival endpoints. Hazard ratios were determined using Cox proportional hazard model. Logistic regression was used to predict objective responses and to determine odds ratio. The need for adjustment by common biomarkers was considered in the Results section part II and III. The Cox model with interaction term was used to compare effects in subgroups in the Results section part III. Optimal cut points of continuous variables with respect to the survival endpoints were determined using the conditional hazard function which was estimated using smoothing techniques based on kernel methods [35]. Statistical comparison of two Treg quantification approaches was performed using Bland-Altman plot and Passing-Bablok regression in MS Excel. Conditional hazard functions were estimated in MATLAB, other analyses were performed in $R$, a language and environment for statistical computing ( $\mathrm{R}$ Core Team, 2013). Results with $p<0.05$ were considered statistically significant.

\section{Results}

Circulating Tregs, $\mathrm{CD} 8^{+}$CTLs and CD8:Treg ratio in metastatic colorectal cancer patients in the context of primary tumor sidedness and KRAS status

Relative and absolute numbers of circulating immune cells were quantified in mCRC patients at the initiation of 1st line anti-VEGF-based therapy and were evaluated in the context of primary tumor sidedness and KRAS status. Regardless of primary tumor sidedness, there was no difference in circulating Treg or $\mathrm{CD} 8^{+} \mathrm{CTL}$ count. A trend was observed toward an increasing proportion of $\mathrm{CD}^{+}$CTLs in T cells from proximal to distal tumor locations. Notably, KRAS wt colorectal cancers exhibited a significantly higher proportion of $\mathrm{CD}^{+}$CTLs among $\mathrm{T}$ cells but also higher Treg measures (absolute count and the proportion of Tregs among $\mathrm{CD} 4^{+}$ cells (Table 1, Fig. 2).

\section{Circulating Tregs, CD8 ${ }^{+}$CTLs, CD8:Treg ratio, and clinical} outcome of 1 st-line anti-VEGF-based therapy of mCRC Median length of follow-up was 77.4 months. Median PFS for the study group was 10.5 months (95\% CI: $8.8-$ 16.3 months), median overall survival was 30.0 months (95\% CI: 23.3-38.5 months), and ORR was 55.6\% (95\% CI: $39.6-70.5 \%)$. Survival and response rate analysis was performed for parameters clinically relevant for metastatic colorectal cancer, such as gender, age, M0 vs. M1, number of metastatic sites, KRAS status, and primary tumor sidedness (Fig. 3). Of those, age $<65$ years was associated with shorter PFS and OS but not ORR (Fig. 3). Levels of circulating immune cells at 1st-line anti-VEGF therapy initiation were investigated in the context of clinical outcome using the conditional hazard function estimated by smoothing techniques (Additional file 1: Figure S2). Cut-off levels for each parameter, dividing cases to "low" and "high", were established as shown in Additional file 1: Figure S2 and subgroups defined by levels of immune parameters were analyzed for PFS and OS (Fig. 3). Of those, the baseline proportion of Tregs in $\mathrm{CD}^{+}$cells was predictive for shorter PFS and OS and worse ORR, and the baseline CD8:Treg ratio was predictive for longer PFS and OS. In the subgroup of mCRC patients with $<6 \%$ frequency of Tregs among $\mathrm{CD}_{4}^{+}$ cells, median PFS (mPFS) was 16.2 months, mOS was 38.5 months, and ORR was $76.4 \%$ compared to those with a high frequency of circulating Tregs of $\geq 6 \%$ among $\mathrm{CD} 4{ }^{+}$cells which had a mPFS of 8.8 months, mOS of 22.3 months, and ORR of $36.8 \%$. In the subgroup of mCRC patients with a high CD8:Treg ratio of $\geq 10$, mPFS was 12.6 months and mOS was 37.8 months compared to those with a ratio of circulating CD8:Treg of $<10$ which had an mPFS of 8.1 months and mOS of 21.0 months (Additional file 1: Table S2).

\section{Circulating Tregs, CD8 ${ }^{+}$CTLs and CD8:Treg ratio and the clinical outcome of anti-VEGF-based therapy of mCRC in the context of primary tumor sidedness}

The association between number of circulating immune cells and clinical outcome of mCRC therapy was further analyzed in the context of primary tumor sidedness (Fig. 4). The predictive value of the baseline proportion of Tregs among $\mathrm{CD} 4^{+}$cells and the CD8:Treg ratio had the same direction in primary right- and left-sided mCRC. In addition to the strong association between high CD8:Treg 
Table 1 Medians of circulating immune cells in mCRC patient subgroups

\begin{tabular}{|c|c|c|c|c|c|c|c|}
\hline & \multirow[t]{2}{*}{$\mathrm{mCRC}$} & \multicolumn{3}{|c|}{ Primary tumor location } & \multicolumn{3}{|c|}{ KRAS status } \\
\hline & & right c. & left c. & r.s./rectum & KRAS wt & & \\
\hline 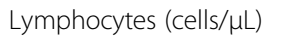 & 1445 & 1593 & 1469 & 1309 & 1521 & & 1312 \\
\hline $\mathrm{CD}^{+}$in lymphocytes (\%) & 63 & 65 & 71 & 59 & 64 & & 65 \\
\hline T cell count (cells/ML) & 1042 & 1137 & 1151 & 894 & 1220 & & 894 \\
\hline $\mathrm{CD}^{+}$in T cells (\%) & 44 & 38 & 44 & 48 & 45 & $*$ & 38 \\
\hline $\mathrm{CD}^{+}$count (cells $\left./ \mu \mathrm{L}\right)$ & 380 & 372 & 511 & 401 & 558 & & 309 \\
\hline Treg in lymphocytes (\%) & 1.9 & 1.7 & 2.0 & 2.0 & 2.3 & & 1.7 \\
\hline Treg in $\mathrm{CD}^{+}(\%)$ & 6.2 & 5.3 & 6.5 & 7.2 & 7.0 & $* *$ & 4.4 \\
\hline 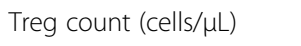 & 26.5 & 33.0 & 37.9 & 25.4 & 38.5 & $*$ & 23.0 \\
\hline CD8:Treg & 13.1 & 10.9 & 13.3 & 15.7 & 11.5 & & 14.0 \\
\hline
\end{tabular}

Stars indicate statistically significant difference in mCRC patients between respective subgroups: ${ }^{*} p<0.05$, ${ }^{* *} p<0.005$. c, colon; r.s., rectosigma

ratio and favorable clinical outcome in the entire study group, the association between high CD8:Treg ratio and longer overall survival was significantly higher in primary right-sided mCRC (Fig. 4, Additional file 1: Figure S3) and those with a high CD8:Treg ratio of $\geq 10$ had a mPFS of 14.4 months and a mOS of 39.9 months compared to those with a low ratio of circulating CD8:Treg of $<10$ which had a mPFS 7.1 months and a mOS of 12.9 months (Additional file 1: Table S2). In the subgroup of mCRC patients with primary tumors in the right colon, a significant interaction between primary tumor sidedness and the predictive value of absolute $\mathrm{T}$ cell count as well as the absolute $\mathrm{CD}^{+}$and $\mathrm{CD}^{+}$cell counts revealed an association of poor PFS and OS with low baseline circulating absolute $\mathrm{T}$ cells or $\mathrm{CD}^{+}$CTLs (Fig. 4, Additional file 1: Table S2 and Figure S3).

\section{Discussion}

Here we show that the baseline level of parameters derived from circulating Tregs, namely the Treg proportion among $\mathrm{CD} 4^{+} \mathrm{T}$ cells and the $\mathrm{CD} 8$ :Treg ratio, at the initiation of anti-VEGF-based therapy predicts treatment

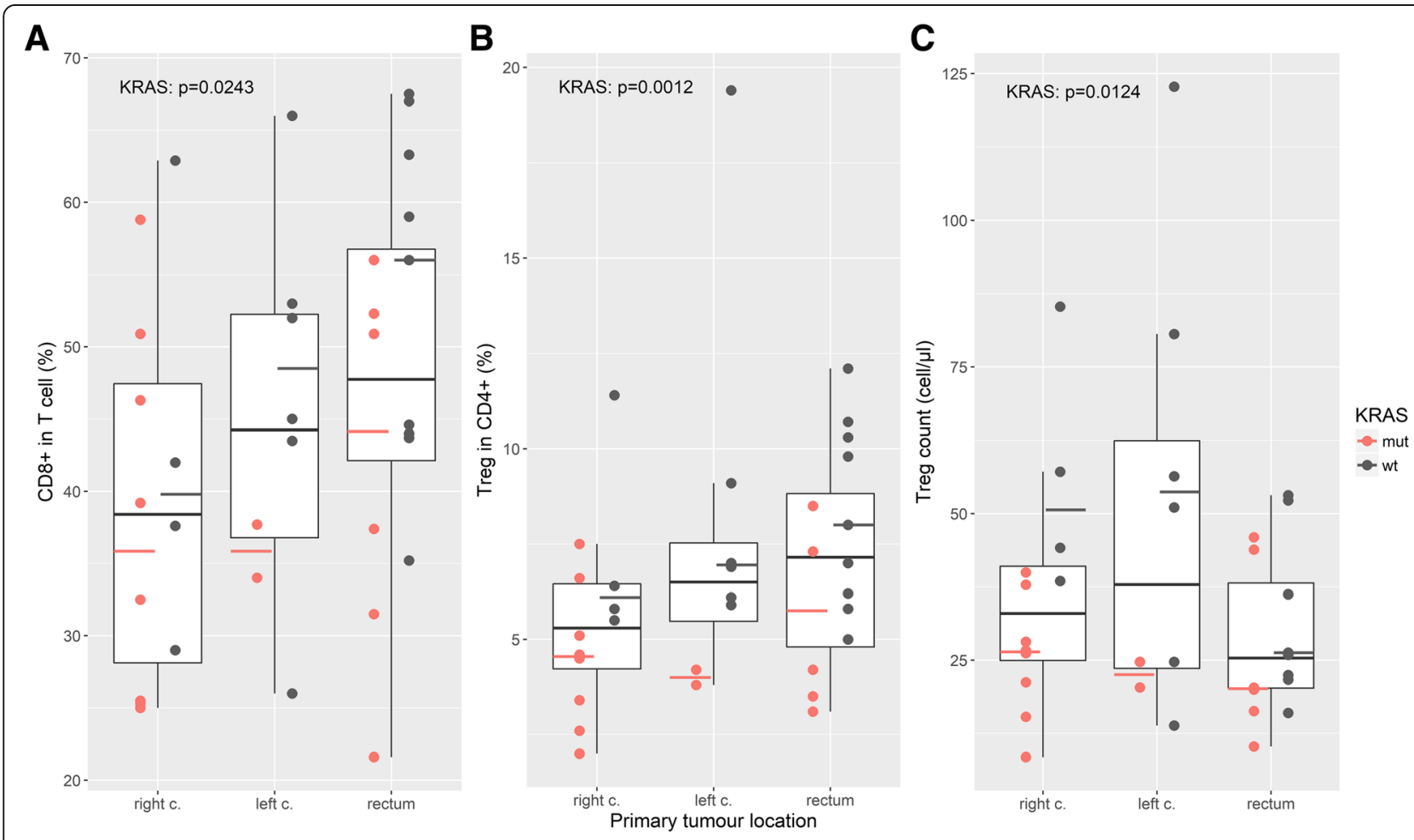

Fig. 2 Circulating CTLS and Tregs in metastatic colorectal cancer patients in the context of primary tumor sidedness and KRAS mutation. $p$-values refer to the level of circulating T cell subsets in KRAS wt vs. KRAS mut in the entire study group 


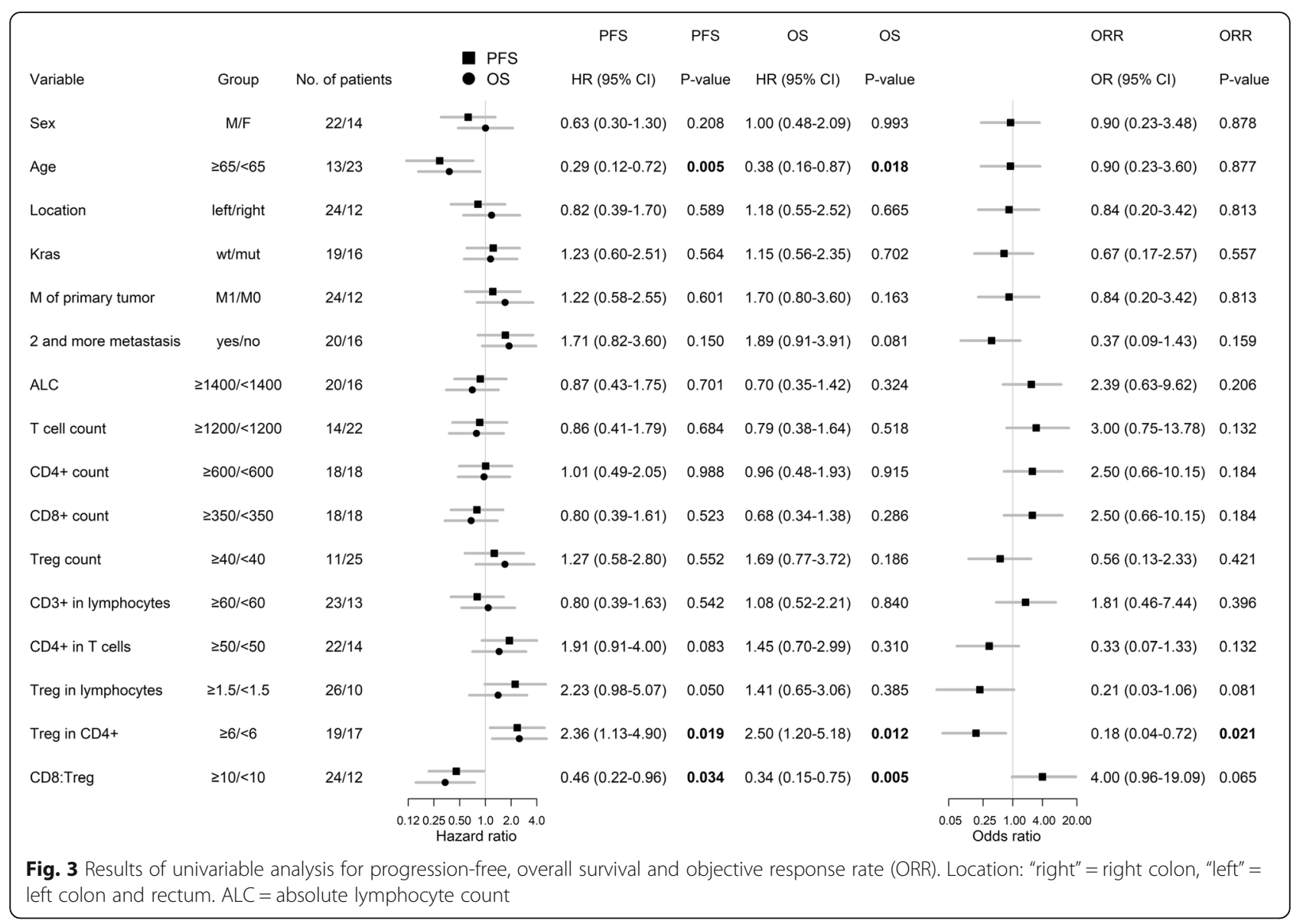

outcome in terms of both PFS and OS, and objective response rate. Our findings are in agreement with a study by Roselli et al. by showing that a low baseline proportion of Tregs in PBMC, but not any other clinical or laboratory parameter evaluated, is associated with favorable outcome in $\mathrm{mCRC}$ patients receiving 1st-line FOLFIRI plus bevacizumab [36]. Roselli et al. emphasized the unexplained lack of association between clinical outcome and $\mathrm{CD}^{+} \mathrm{T}$ cells [36] that we also observed when baseline circulating immune parameters from mCRC patients were analyzed irrespective of primary tumor sidedness. Nevertheless, and based on our previous findings of poor clinical outcome of mCRC patients with primary tumors in the right colon [37] and the differential impact of KRAS status for 1st-line anti-VEGF-based therapy in primary right vs. left-sided mCRC [38], we analyzed circulating immune cells in the context of primary tumor sidedness, revealing that the association of previously identified Treg-associated biomarkers, as well as a baseline number of circulating $\mathrm{CD}^{+}$ $\mathrm{T}$ cells, with clinical outcome of 1st-line anti-VEGF-based therapy is particularly strong in mCRC patients with primary tumor in the right colon.

The differential disease behavior of primarily right vs. left-sided mCRC is substantiated by the prevalence of distinct colorectal cancer subtypes within the colon and rectum [39]. Based on the association of the immuneactivated, highly immunogenic CMS1 tumor subtype with right-sided tumor location [39] on the one hand, and the strong association of favorable circulating immune signature (low Tregs, high $\mathrm{CD}^{+} \mathrm{T}$ cells, high $\mathrm{CD} 8$ :Treg ratio) and favorable clinical outcome in primary right-sided $\mathrm{mCRC}$ on the other, we propose that right-sided mCRC patients with favorable circulating immune signature overlap with a subgroup of patients with immune-activated tumors that clearly benefit from immunomodulatory anti-VEGF-based therapy. Our hypothesis that immune characteristics in the TME are reflected in the circulation is further supported by the finding of an association of KRAS mutant status with reduction in both $\mathrm{CD}^{+} \mathrm{T}$ cell count and number of Tregs. CMS2 and 3 subtypes are associated with reduced immune infiltration and reactivity, and this immune quiescence is more profound in KRAS-mutated tumors [40] and is likely mirrored in peripheral blood.

Due to the small size of study group, the cut-off levels of immune cells stratifying prognostic subgroups may not be accurate and should be validated in larger cohort of patients. Limited size of the study group also did not allow multivariable analysis. A strength of this study is its long- 


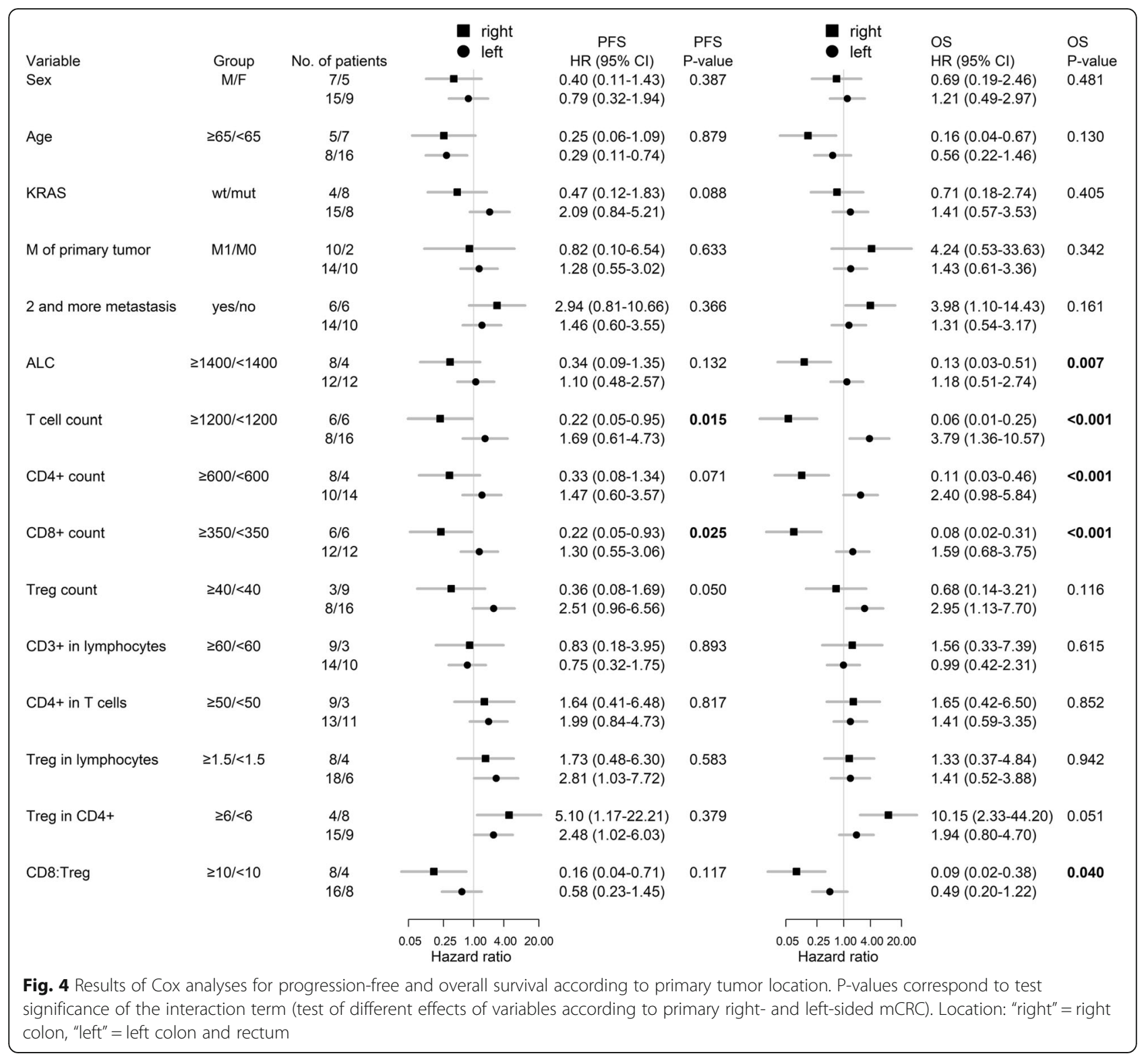

term follow-up. On the other hand, during the time period when the study was designed, biomarkers such as $N R A S, B R A F$, and MSI were just emerging in the clinical practice of colorectal cancer patient management and unfortunately were not analyzed in the context of circulating immune cells in mCRC treatment with bevacizumab. Thus, it remains to be investigated whether the subset of patients with right-sided tumor and favorable circulating immune signature overlaps with the MSI-H/CMS1 subset and may therefore be a good candidate for immunotherapy with checkpoint inhibitors. Also, it remains to be addressed whether mCRC patients, particularly those with right-sided tumors with an immunosuppressive circulating immune signature (high Tregs, low $\mathrm{CD}^{+} \mathrm{T}$ cells and/or low CD8:Treg ratio) would benefit from the aggressive, triple combination chemotherapy regimen FOLFOXIRI [41].

\section{Conclusions}

Circulating immune parameters derived from the baseline level of $\mathrm{CD}^{+}$CTLs and Tregs may predict clinical outcome following 1st-line treatment with the anti-VEGF angio/immunomodulatory agent bevacizumab and thereby identify mCRC patients, particularly within the primarily right-sided subgroup, who have favorable outcome. 


\section{Additional files}

Additional file 1: Table S1. Baseline characteristics of $\mathrm{mCRC}$ patients included in the study. Figure S1. Gating strategy for $\mathrm{CD}^{+}{ }^{+} \mathrm{CD} 4^{+} \mathrm{CD} 25^{+} \mathrm{CD} 127^{- \text {low }}$ cells and the analytical comparability of a) $\mathrm{CD} 25^{+} \mathrm{CD} 127^{- \text {low }+}$ and b) $\mathrm{CD}_{2} 5^{+} \mathrm{FoxP}^{+}$quantification approaches. Statistical comparison of these approaches using c) Bland-Altman plot and d) Passing-Bablok regression. Figure S2. Determination of the optimal cut points for circulating immune cells with respect to PFS and OS using kernel estimates of conditional hazard functions. Table S2. Characteristics of clinical outcome (PFS and OS), proportion of Tregs in the $\mathrm{CD}^{+}$cell subset, and the CD8: Treg ratio. Figure S3. Circulating immune cells and clinical outcome of anti-VEGF-based therapy of mCRC in the context of primary tumor sidedness. (DOCX $2640 \mathrm{~kb}$ )

Additional file 2: Spreadsheet with data generated and analyzed during the study. (XLSX $20 \mathrm{~kb}$ )

\section{Abbreviations}

ALC: absolute lymphocyte count; CMS: Consensus molecular subtype; CR: complete remission; CTLs: Cytotoxic CD8 ${ }^{+} T$ cells; CTx: chemotherapy; iTregs: induced (or inducible) Tregs; IV: intravenous; mCRC: metastatic colorectal cancer; NA: Not Available; NS: not specified; nTregs: natural Treg cells; ORR: objective response rate; OS: overall survival; PD: progressive disease; PFS: progression-free survival; PO: per os; PR: partial remission; PS: performance status; SD: stable disease; TME: tumor microenvironment; Tregs: Regulatory T cells

\section{Acknowledgements}

Not applicable.

\section{Authors' contributions}

BB conceived of the study, participated in its design, performed patient accrual, contributed to data interpretation, supervised data collection and management, and drafted the manuscript. EB participated on the study design, performed data analysis and statistical analysis, contributed to data interpretation. IS performed statistical analysis, prepared figures and tables, contributed to data interpretation, and drafted the manuscript. KP supervised data collection, supervised laboratory testing, contributed to figure and table preparation, and drafted the manuscript. LF contributed to data collection, contributed to laboratory testing and laboratory data analysis. KG contributed to data collection, contributed to laboratory testing, and drafted the manuscript. RN contributed to data interpretation, reviewed and edited the manuscript. DV contributed to data interpretation, reviewed and edited the manuscript. RO performed patient accrual, contributed to data interpretation, reviewed and edited the manuscript. MAS contributed to data interpretation, reviewed and edited the manuscript. LZ-D conceived of the study design, coordinated the study, contributed to data analysis and interpretation, drafted and finalized the manuscript. All authors read and approved the final manuscript

\section{Funding}

The work was supported by the Czech Ministry of Health for projects AZV 16-31966A (data interpretation) and DRO 00209805 (design of the study, writing the manuscript) and the Czech Ministry of Education, Youth and Sports for projects LO1413 (sample and data analysis, writing the manuscript) and LM2015089 (sample collection).

\section{Availability of data and materials}

All data generated and analysed during this study are included in this published article (Additional file 2).

\section{Ethics approval and consent to participate}

The study was performed in compliance with the Declaration of Helsinki, was approved by the Ethics Committee of Masaryk Memorial Cancer Institute (MMCI, Brno, Czech Republic; reference number MOU/EK/131210) and written informed consent was obtained from all patients.

\section{Consent for publication}

Not applicable.

\section{Competing interests}

The authors declare that they have no competing interests.

\section{Author details}

${ }^{1}$ Department of Comprehensive Cancer Care, Masaryk Memorial Cancer Institute, Brno, Czech Republic. ${ }^{2}$ Regional Centre for Applied Molecular Oncology, Masaryk Memorial Cancer Institute, Brno, Czech Republic. ${ }^{3}$ Department of Laboratory Medicine, Masaryk Memorial Cancer Institute, Brno, Czech Republic. ${ }^{4}$ Department of Oncological and Experimental pathology, Masaryk Memorial Cancer Institute, Brno, Czech Republic.

\section{Received: 8 October 2018 Accepted: 8 July 2019}

Published online: 15 July 2019

\section{References}

1. Titu LV, Monson JR, Greenman J. The role of CD8(+) T cells in immune responses to colorectal cancer. Cancer Immunol Immunother. 2002;51(5):235-47.

2. Chiba T, Ohtani H, Mizoi T, Naito Y, Sato E, Nagura H, Ohuchi A, Ohuchi K, Shiiba K, Kurokawa Y, et al. Intraepithelial CD8+ T-cell-count becomes a prognostic factor after a longer follow-up period in human colorectal carcinoma: possible association with suppression of micrometastasis. Brit J Cancer. 2004;91(9):1711-7.

3. Naito Y, Saito K, Shiiba K, Ohuchi A, Saigenji K, Nagura H, Ohtani H. CD8+ T cells infiltrated within cancer cell nests as a prognostic factor in human colorectal cancer. Cancer Res. 1998;58(16):3491-4.

4. Oberg A, Samii S, Stenling R, Lindmark G. Different occurrence of CD8+, CD45R0+, and CD68+ immune cells in regional lymph node metastases from colorectal cancer as potential prognostic predictors. Int J Color Dis 2002;17(1):25-9.

5. Ohtani H. Focus on TILs: prognostic significance of tumor infiltrating lymphocytes in human colorectal cancer. Cancer Immun. 2007;7:4.

6. Mlecnik B, Tosolini M, Kirilovsky A, Berger A, Bindea G, Meatchi T, Bruneval P, Trajanoski Z, Fridman WH, Pages F, et al. Histopathologic-based prognostic factors of colorectal cancers are associated with the state of the local immune reaction. J Clin Oncol. 2011;29(6):610-8.

7. Galon J, Mlecnik B, Bindea G, Angell HK, Berger A, Lagorce C, Lugli A, Zlobec I, Hartmann A, Bifulco C, et al. Towards the introduction of the 'Immunoscore' in the classification of malignant tumours. J Pathol. 2014; 232(2):199-209.

8. Taube JM, Klein A, Brahmer JR, Xu H, Pan X, Kim JH, Chen L, Pardoll DM, Topalian SL, Anders RA. Association of PD-1, PD-1 ligands, and other features of the tumor immune microenvironment with response to anti-PD1 therapy. Clin Cancer Res. 2014;20(19):5064-74.

9. Sakaguchi S, Miyara M, Costantino CM, Hafler DA. FOXP3+ regulatory T cells in the human immune system. Nat Rev Immunol. 2010;10(7):490-500.

10. Whiteside TL. What are regulatory $T$ cells (Treg) regulating in cancer and why? Semin Cancer Biol. 2012;22(4):327-34.

11. Langier S, Sade K, Kivity S. Regulatory T cells: the suppressor arm of the immune system. Autoimmun Rev. 2010;10(2):112-5.

12. Ling KL, Pratap SE, Bates GJ, Singh B, Mortensen NJ, George BD, Warren BF, Piris J, Roncador G, Fox SB, et al. Increased frequency of regulatory $T$ cells in peripheral blood and tumour infiltrating lymphocytes in colorectal cancer patients. Cancer Immun. 2007;7:7.

13. Sundstrom $P$, Stenstad $H$, Langenes $V$, Ahlmanner F, Theander $L$, Ndah TG, Fredin K, Borjesson L, Gustavsson B, Bastid J, et al. Regulatory T cells from Colon Cancer patients inhibit effector T-cell migration through an adenosine-dependent mechanism. Cancer Immunol Res. 2016:4(3):183-93.

14. Ward-Hartstonge KA, Kemp RA. Regulatory T-cell heterogeneity and the cancer immune response. Clin Transl Immunol. 2017:6(9):e154.

15. Luu M, Steinhoff U, Visekruna A. Functional heterogeneity of gut-resident regulatory T cells. Clin Transl Immunol. 2017;6(9):e156.

16. Salama P, Phillips M, Grieu F, Morris M, Zeps N, Joseph D, Platell C, lacopetta B. Tumor-infiltrating FOXP3+ T regulatory cells show strong prognostic significance in colorectal cancer. J Clin Oncol. 2009;27(2):186-92.

17. Zhuo C, Xu Y, Ying M, Li Q, Huang L, Li D, Cai S, Li B. FOXP3+ Tregs: heterogeneous phenotypes and conflicting impacts on survival outcomes in patients with colorectal cancer. Immunol Res. 2015;61(3):338-47.

18. Tosolini M, Kirilovsky A, Mlecnik B, Fredriksen T, Mauger S, Bindea G, Berger A, Bruneval P, Fridman WH, Pages F, et al. Clinical impact of different classes of infiltrating T cytotoxic and helper cells (Th1, th2, treg, th17) in patients with colorectal cancer. Cancer Res. 2011;71(4):1263-71. 
19. Verma C, Eremin JM, Robins A, Bennett AJ, Cowley GP, El-Sheemy MA, Jibril JA, Eremin O. Abnormal T regulatory cells (Tregs: FOXP3+, CTLA-4+), myeloid-derived suppressor cells (MDSCs: monocytic, granulocytic) and polarised T helper cell profiles (Th1, Th2, Th17) in women with large and locally advanced breast cancers undergoing neoadjuvant chemotherapy (NAC) and surgery: failure of abolition of abnormal treg profile with treatment and correlation of treg levels with pathological response to NAC. J Transl Med. 2013;11:16.

20. Yamamoto T, Yanagimoto H, Satoi S, Toyokawa H, Hirooka S, Yamaki S, Yui R, Yamao J, Kim S, Kwon AH. Circulating CD4+CD25+ regulatory T cells in patients with pancreatic cancer. Pancreas. 2012;41(3):409-15.

21. Ihara F, Sakurai D, Horinaka A, Makita Y, Fujikawa A, Sakurai T, Yamasaki K, Kunii N, Motohashi S, Nakayama T, et al. CD45RA(-)Foxp3(high) regulatory T cells have a negative impact on the clinical outcome of head and neck squamous cell carcinoma. Cancer Immunol Immunother. 2017;66(10):1275-85.

22. Jass JR. Classification of colorectal cancer based on correlation of clinical, morphological and molecular features. Histopathology. 2007:50(1):113-30.

23. Budinska E, Popovici V, Tejpar S, D'Ario G, Lapique N, Sikora KO, Di Narzo AF, Yan P, Hodgson JG, Weinrich S, et al. Gene expression patterns unveil a new level of molecular heterogeneity in colorectal cancer. J Pathol. 2013;231(1):63-76.

24. Sadanandam A, Lyssiotis CA, Homicsko K, Collisson EA, Gibb WJ, Wullschleger S, Ostos LC, Lannon WA, Grotzinger C, Del Rio M, et al. A colorectal cancer classification system that associates cellular phenotype and responses to therapy. Nat Med. 2013;19(5):619-25.

25. Dienstmann R, Vermeulen L, Guinney J, Kopetz S, Tejpar S, Tabernero J. Consensus molecular subtypes and the evolution of precision medicine in colorectal cancer. Nat Rev Cancer. 2017;17(2):79-92.

26. Popat S, Hubner R, Houlston RS. Systematic review of microsatellite instability and colorectal cancer prognosis. J Clin Oncol. 2005;23(3):609-18.

27. Deschoolmeester $V$, Baay M, Lardon F, Pauwels P, Peeters M. Immune cells in colorectal Cancer: prognostic relevance and role of MSI. Cancer Microenviron. 2011:4(3):377-92.

28. Boissiere-Michot F, Lazennec G, Frugier H, Jarlier M, Roca L, Duffour J, Du Paty E, Laune D, Blanchard F, Le Pessot F, et al. Characterization of an adaptive immune response in microsatellite-instable colorectal cancer. Oncoimmunology. 2014;3:e29256

29. Bencsikova B, Bortlicek Z, Halamkova J, Ostrizkova L, Kiss I, Melichar B, Pavlik T, Dusek L, Valik D, Vyzula R, et al. Efficacy of bevacizumab and chemotherapy in the first-line treatment of metastatic colorectal cancer: broadening KRAS-focused clinical view. BMC Gastroenterol. 2015;15:37.

30. Alfaro C, Suarez N, Gonzalez A, Solano S, Erro L, Dubrot J, Palazon A, HervasStubbs S, Gurpide A, Lopez-Picazo JM, et al. Influence of bevacizumab, sunitinib and sorafenib as single agents or in combination on the inhibitory effects of VEGF on human dendritic cell differentiation from monocytes. British J Cancer. 2009;100(7):1111-9.

31. Osada T, Chong G, Tansik R, Hong T, Spector N, Kumar R, Hurwitz HI, Dev I, Nixon AB, Lyerly HK, et al. The effect of anti-VEGF therapy on immature myeloid cell and dendritic cells in cancer patients. Cancer Immunol Immunother. 2008;57(8):1115-24.

32. Wada J, Suzuki H, Fuchino R, Yamasaki A, Nagai S, Yanai K, Koga K, Nakamura M, Tanaka M, Morisaki T, et al. The contribution of vascular endothelial growth factor to the induction of regulatory T-cells in malignant effusions. Anticancer Res. 2009;29(3):881-8.

33. Terme M, Tartour E, Taieb J. VEGFANEGFR2-targeted therapies prevent the VEGFA-induced proliferation of regulatory $T$ cells in cancer. Oncoimmunology. 2013;2(8):e25156.

34. Manzoni M, Rovati B, Ronzoni M, Loupakis F, Mariucci S, Ricci V, Gattoni E, Salvatore L, Tinelli C, Villa E, et al. Immunological effects of bevacizumab-based treatment in metastatic colorectal cancer. Oncology. 2010;79(3-4):187-96.

35. Selingerova I, Dolezelova H, Horova I, Katina S, Zelinka J. Survival of patients with primary brain tumors: comparison of two statistical approaches. PLoS One. 2016;11(2):e0148733.

36. Roselli M, Formica V, Cereda V, Jochems C, Richards J, Grenga I, Orlandi A, Ferroni P, Guadagni F, Schlom J. The association of clinical outcome and peripheral T-cell subsets in metastatic colorectal cancer patients receiving firstline FOLFIRI plus bevacizumab therapy. Oncoimmunology. 2016;5(7):e1188243.

37. Ostrizkova L, Petruzelka L, Hejduk K, Zdrazilova-Dubska L, Vocka M, Brancikova D, Bencsikova B, Vyzula R, Obermannova R. Right-sided colon cancer is associated with increased frequency of KRAS mutation and with a poor outcome in patients with metastatic disease treated in the first line with bevacizumab and chemotherapy. Annals Oncol. 2016;27(Suppl 2):114-5.
38. Obermannova R, Ostrizkova L, Hejduk K, Zdrazilova-Dubska L, Vocka M, Vyzula R, Bencsikova B, Petruzelka L. Right-sided versus left-sided primary tumor location in patients with KRASmut metastatic colorectal cancer (mCRC) treated with 1st-line anti-VEGF plus chemotherapy (CTx) - data from the National Czech Registry. Annals Oncol. 2016;27(Suppl 9):1680.

39. Loree JM, Pereira AAL, Lam M, Willauer AN, Raghav K, Dasari A, Morris VK, Advani S, Menter DG, Eng C, et al. Classifying colorectal Cancer by tumor location rather than sidedness highlights a continuum in mutation profiles and consensus molecular subtypes. Clin Cancer Res. 2018;24(5):1062-72.

40. Lal N, White BS, Goussous G, Pickles O, Mason MJ, Beggs AD, Taniere P, Willcox BE, Guinney J, Middleton GW. KRAS mutation and consensus molecular subtypes 2 and 3 are independently associated with reduced immune infiltration and reactivity in colorectal Cancer. Clin Cancer Res. 2018;24(1):224-33.

41. Cremolini C, Loupakis F, Antoniotti C, Lupi C, Sensi E, Lonardi S, Mezi S, Tomasello G, Ronzoni M, Zaniboni A, et al. FOLFOXIRI plus bevacizumab versus FOLFIRI plus bevacizumab as first-line treatment of patients with metastatic colorectal cancer: updated overall survival and molecular subgroup analyses of the open-label, phase 3 TRIBE study. Lancet Oncol. 2015;16(13):1306-15.

\section{Publisher's Note}

Springer Nature remains neutral with regard to jurisdictional claims in published maps and institutional affiliations.
Ready to submit your research? Choose BMC and benefit from:

- fast, convenient online submission

- thorough peer review by experienced researchers in your field

- rapid publication on acceptance

- support for research data, including large and complex data types

- gold Open Access which fosters wider collaboration and increased citations

- maximum visibility for your research: over $100 \mathrm{M}$ website views per year

At BMC, research is always in progress.

Learn more biomedcentral.com/submissions 